\title{
Spectroscopic studies on lipoprotein structure modification under oxidative stress
}

\author{
Andreia Tache ${ }^{\mathrm{a}, \mathrm{b}, *}$, Simona-Carmen Litescu ${ }^{\mathrm{a}}$ and Gabriel-Lucian Radu ${ }^{\mathrm{a}, \mathrm{b}}$ \\ ${ }^{a}$ National Institute for Biological Sciences, Center of Bioanalysis, Bucharest, Romania \\ ${ }^{\mathrm{b}}$ University "Polytechnica" of Bucharest, Faculty of Applied Chemistry and Materials Science, \\ Bucharest, Romania
}

\begin{abstract}
Matrix assisted laser desorption-ionization time of flight (MALDI-ToF) and infrared techniques were used to study oxidative modification of low density lipoproteins (LDL), considered to have the key role in biological process that initiates and accelerates the development of cardiovascular disease. The early identification of lipoperoxidation products creates the opportunity of the efficient prevention of eventual oxidative damages. MALDI analysis of LDL subjected to in vitro oxidation process initiated by 2,2-azobis(2-amidinopropane) dihydrochloride revealed that some fragments of lipoprotein changed the molecular weight by 16 and 32 Da due to the oxygen or hydroxyl groups attachment, and peroxide or hydroperoxide formation, while Fourier Transformed Infrared studies proved that lipoprotein changes its protein secondary conformation from predominantly $\alpha$-helix in predominantly $\beta$-turn. The increase in free radicals concentration correlated to structural changes, and the presence of transitional metal ion, copper (II), in the oxidation process lead to an enhancing of the damaging effects of free radicals on lipoprotein substrate. It was shown that the toxic effects of oxidants are delayed by the presence of glutathione (10 $\mathrm{mM})$, an endogenous antioxidant.
\end{abstract}

Keywords: MALDI-ToF, FT-IR, lipoperoxidation, $\mathrm{Cu}^{2+}$, glutathione

\section{Introduction}

Low density lipoproteins (LDL) are the main target of reactive oxygen species (ROS) "attack" on cellular level. LDL oxidation is an important step in the initiation and development of various pathological states such as cardio-vascular diseases that are among the primary causes of death in developed countries [14,29]. Following peroxidation, bio-macromolecules changes its structure forming various oxidation products, which can be less (ketones, aldehydes) or more reactive (peroxy and alkoxy radicals) [4]. It was proven [2,27,31] that oxidation products can be used as biomarkers for pathological states. There are different analytical methods for lipoperoxide assessment: UV spectroscopy [6,17], IR spectroscopy [7,22], fluorescence [21], chromatographic [12,13], colorimetry [34], titrimetry [18], mass spectrometry [35], bio-sensors analysis $[19,28]$ but it is no standard method that can be generally used to characterize the lipoperoxidation.

Numerous factors are influencing the lipoperoxidation process, one of them being the presence of transitional metals (iron, copper) that induce free radicals formation [36], accelerating the oxidation process. Also, lipoperoxidation may be delayed or prevented by antioxidant (Aox) compounds, which are able to transform the reactive species into non-toxic radicals thus ending the oxidation process $[3,5$,

\footnotetext{
${ }^{*}$ Corresponding author: Andreia Tache, University Polytechnica of Bucharest, Faculty of Applied Chemistry and Materials Science, Bucharest 010737, Romania. Tel./Fax: +40 2122 00900; E-mail: tache_andreia@yahoo.co.uk.
} 
24,26]; glutathione (GSH) is recognized as one of the most important endogenous antioxidants, able to play as the first major defense system against ROS [10,32].

In this paper we provide information on structural changes of a bio-macromolecule - considered as substrate for peroxidation, namely low-density lipoproteins (LDL) - due to noxious effects of prooxidant compounds, studies being performed by using Matrix assisted laser desorption-ionization time of flight (MALDI-ToF) analysis and Fourier transform infrared (FT-IR) spectrometry. In the same time the preservative effects of an endogenous antioxidant, glutathione, was assessed.

It was demonstrated [9] that LDL behavior in vivo is similar to that in vitro, leading to the conclusion that lipoprotein peroxidation model is useful in characterizing the effects of free radicals and antioxidants on human body. Therefore, the study of LDL oxidation products obtained after ROS attack in the absence and presence of antioxidants was considered a reasonable approach in order to evaluate the toxic effects of free radicals respectively the protective effects of antioxidants on organisms, using LDL as substrate for oxidative stress.

MALDI-ToF has emerged as an important technique for analyzing and characterizing large biomolecules of various complexities. MALDI is a soft ionization technique that allows analysis of intact molecule and has been widely used for analysis of peptides, proteins and lipids [25] providing information about the primary structure and about changes in their molecular mass after the action of different damaging agents.

Almost all molecules absorb in infrared and each type of molecule absorbs at certain frequencies leading to a unique absorption spectra (fingerprint). Any change in the structure of analyzed molecules lead to the modification of FT-IR spectra, this technique being useful in monitor protein conformation and lipid chain order. IR spectrometry is a rapid technique that requires no additional processing of the samples and provides information on the sample surface functional groups. Even if this technique shows limitations in quantitative analysis it can be used to study conformational changes of lipoprotein occurring in the presence of oxidative agents, due to high reproducibility of frequency scale.

\section{Materials and methods}

\subsection{Chemical reagents}

The low density lipoproteins from human plasma (LDL), gold supports (Au), 2,2'-azobis(2methylpropionamidine) dihydrochloride (AAPH), cupric chloride dihydrate $\left(\mathrm{Cu}^{2+}\right)$, acetonitrile $(\mathrm{ACN})$ and trifluoroacetic acid (TFA) were purchased from Sigma-Aldrich, glutathione-reduced form (GSH) were purchased from Merck and the MALDI calibration mixture and matrix were purchased from BioLaser and used without any further purification. All solutions were freshly prepared.

\subsection{LDL oxidation}

Oxidative stress was initiated using different methods, in order to ensure a longer ability of the phenomenon, namely in order to asses both lipoperoxidation and GSH effect and metal ions (II) influence on lipoperoxidation:

(1) AAPH oxidation: LDL was incubated in AAPH solution (of different concentration: 7.35, 22.06, $36.76,51.47$ and $73.53 \mathrm{mM}$ ), which induced the generation of ROS. The generated peroxyl radicals were able to induce lipid peroxidation $[15,23]$. The oxidation conditions were: temperature 25$35^{\circ} \mathrm{C}$ and time $\geqslant 10 \mathrm{~min} ;$ 
(2) $\mathrm{AAPH} / \mathrm{Cu}^{2+}$ oxidation: LDL was incubated in an $\mathrm{AAPH} / \mathrm{Cu}^{+2}$ mixtures; the temperature and time conditions were the same as above.

\subsection{LDL co-immobilization with antioxidants}

LDL immobilization on gold supports was achieved as previously reported [33]. Some of LDL chemically modified gold supports were incubated at $20-25^{\circ} \mathrm{C}$ for $1 \mathrm{~h}$ in a $10 \mathrm{mM}$ GSH solution. GSH concentration was chosen to be similar to that found at cellular level [20]. After incubation, the system was dried in inert atmosphere at room temperature and was used in further analysis.

\subsection{Matrix Assisted Laser Desorption-Ionization Time of Flight (MALDI-ToF)}

MALDI MS spectra were recorded in positive linear mode at room temperature $\left(22^{\circ} \mathrm{C}\right)$ in high vacuum condition $\left(10^{-7}-10^{-9}\right.$ mbarr) using a spectrometer Axima CFR-Plus, Shimadzu-Kratos equipped with nitrogen laser, that operates in pulses and emits at $337 \mathrm{~nm}$. Low mass gate was turned on to prevent the saturation of the detector by ions resulting from the matrix. Sinapinic acid (SA) matrix was used at concentration $5 \mathrm{mg} / \mathrm{ml}$ in $40 \%$ ACN in water: $0.1 \%$ TFA and samples were prepared by sandwich method to get a good signal to noise ratio. These conditions were chosen after several optimization tests (data not shown). To obtain a more accurate mass, the instrument was calibrated using a mixture of standards of known molecular weight and concentration. The calibration mixture included four individual peptides: insulin bovine $\beta$-chain oxidized $(0.5 \mathrm{pmoles} / \mu \mathrm{l})$ which has one positive ion $3496.949 \mathrm{Da}$ mass weight; insulin bovine $(0.5$ pmoles/ $\mu \mathrm{l})$ which has two positive ions of $5734.582 \mathrm{Da}$ (ion with +1 charge) and 2867.795 Da (ion with +2 charge) mass weight; aprotinin $(1.0 \mathrm{pmoles} / \mu \mathrm{l})$ which has two positive ions of $6512.539 \mathrm{Da}$ (ion with +1 charge) and $3256.774 \mathrm{Da}$ (ion with +2 charge) mass weight, and ubiquitin ( $2.5 \mathrm{pmoles} / \mu \mathrm{l}$ ) which has three positive ions of $8565.859 \mathrm{Da}$ (ion with +1 charge), $4283.433 \mathrm{Da}$ (ion with +2 charge) and $2855.958 \mathrm{Da}$ (ion with +3 charge) mass weight, respectively. The calibration method employed was close external, to avoid the overlap phenomenon and to ensure a good mass accuracy. Matrix and calibration mixture were prepared according to supplier specification. All spectra were recorded in the same condition.

\subsection{Fourier Transform Infrared Spectroscopy (FT-IR)}

FT-IR spectra were recorded with the Bruker-Tensor 27 Fourier Transform spectrometer equipped with a RT-DLaTGS detector. Each measurement was recorded in reflectance units in the range 4000$600 \mathrm{~cm}^{-1}$ and average value of 64 co-added scans, with $4 \mathrm{~cm}^{-1}$ resolution and $6 \mathrm{~mm}$ aperture, at room temperature. The spectra were collected and ascribed using Opus software, version 6.0. Samples were placed directly onto the reflectance support set at $45^{\circ}$.

\section{Results and discussion}

\subsection{MALDI-ToF analysis}

The AAPH oxidation was performed using different concentration of azo-initiator and a constant concentration (50 ppm) of oxidizable substrate, namely LDL. 


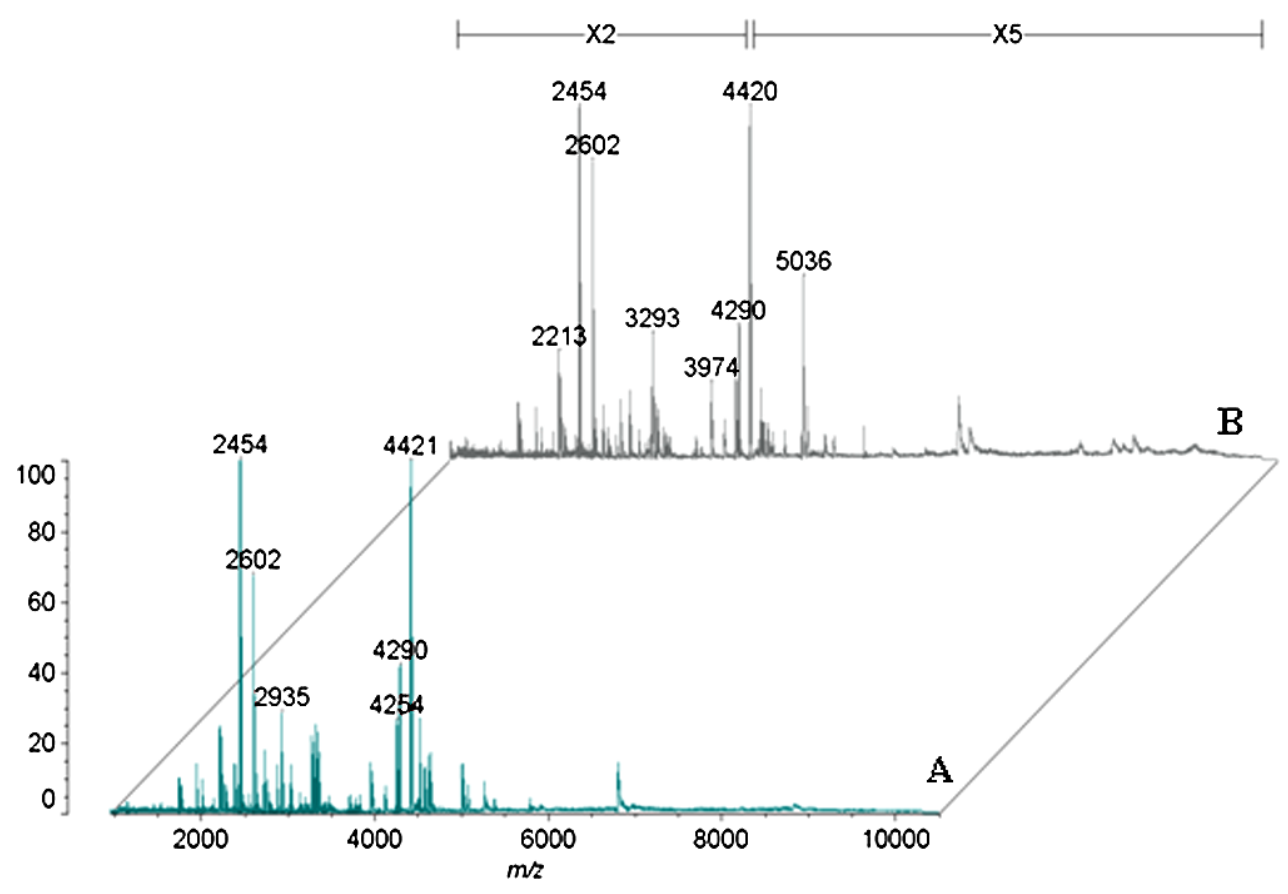

Fig. 1. MALDI MS spectra: (A) LDL native; (B) LDL-oxidized. X2 - signals increased twice, X5 - signals increased five times. (Colors are visible in the online version of the article; http://dx.doi.org/10.3233/SPE-2011-0533.)

MALDI MS spectra of LDL show a large number of ions (about 50), but only some of them, which are considered ions of interest, changed their molecular masses subsequent to oxidation process (Fig. 1). Registered mass change was about 16 and $32 \mathrm{Da}$ and may be due to the attachment of an oxygen atom or hydroxyl groups and respectively peroxide or hydroperoxide group (taking into account the mass tolerance, $\pm 1-5 \mathrm{Da}$ ).

High attention was given to ion fragments whose mass changed. Thus $6810 \mathrm{Da}$ ion fragment disappeared and $6825 \mathrm{Da}$ appeared. 5008 and $5021 \mathrm{Da}$ ion fragments almost disappeared and $5036 \mathrm{Da}$ ion fragment increased in intensity. 4650 and $4522 \mathrm{Da}$ ion fragments almost disappeared, appearing 4665 and $4685 \mathrm{Da}$, respectively 4537 and $4556 \mathrm{Da}$ ion fragments. 3959, 3780, 2766 and $2396 \mathrm{Da}$ ion fragments almost disappeared and 3976, 3796, 2785 and $2414 \mathrm{Da}$ ion fragments respectively increased in intensity. $4376 \mathrm{Da}$ ion fragment signal diminished and the $4390 \mathrm{Da}$ ion fragments appeared.

For small concentration of AAPH, namely $7.35 \mathrm{mM}$ the initial signal decreased in intensity and shown a shoulder (whose mass was 16 Da higher). For concentrations between 22.06-36.76 mM AAPH, the shoulder (+16 Da) stand out and a new shoulder appeared (whose mass was $32 \mathrm{Da}$ higher than the initial ion fragment). At 51.47-73.53 mM AAPH concentration, initial signal turn into a shoulder and ions attributed to LDL oxidation product stand out more. Therefore, the increases of AAPH concentration lead to a greater amount of LDL oxidation products, as results from intensity increasing (Fig. 2).

A time study of the oxidation process (Fig. 3A) was conducted and was noticed a small increase in the intensity of ion fragments of interest for the first $30 \mathrm{~min}$. After this period ion fragments intensity have different evolution. The 4540, 4685 and $6825 \mathrm{Da}$ ion fragments intensities increased with time and after that remained almost constant for about $30 \mathrm{~min}$. After $90 \mathrm{~min}$ the signals started to decrease. The 2785 and $4556 \mathrm{Da}$ ion fragments intensities increased for $60 \mathrm{~min}$, slightly alter for another $30 \mathrm{~min}$ and finally after 90 min the intensity signal decreasing continued. The $5038 \mathrm{Da}$ ion fragment intensity 


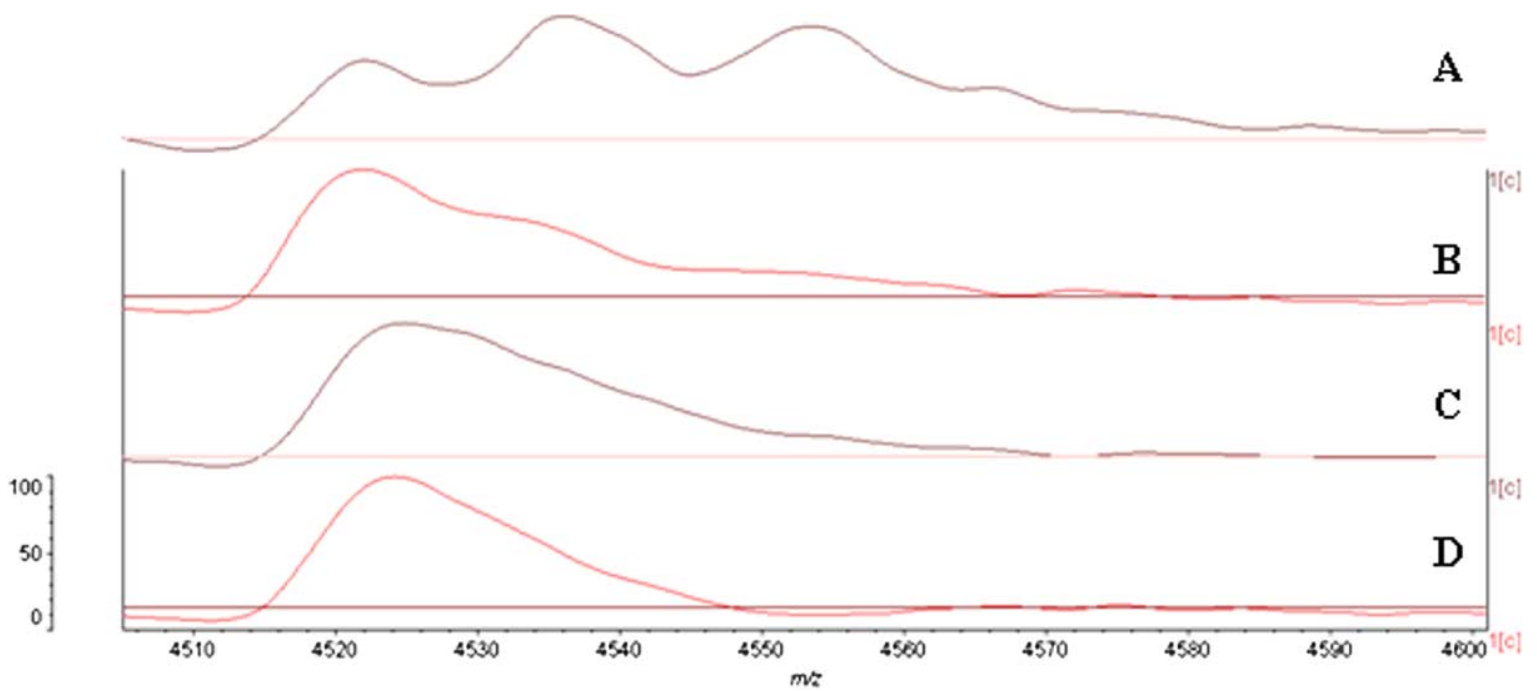

Fig. 2. Variation of the oxidation products intensity with AAPH concentration. (A) $73.53 \mathrm{mM}$ AAPM; (B) $36.76 \mathrm{mM}$ AAPH; (C) $7.35 \mathrm{mM} \mathrm{AAPH}$; (D) $0 \mathrm{mM}$ AAPH. (Colors are visible in the online version of the article; http://dx.doi.org/10.3233/ SPE-2011-0533.)
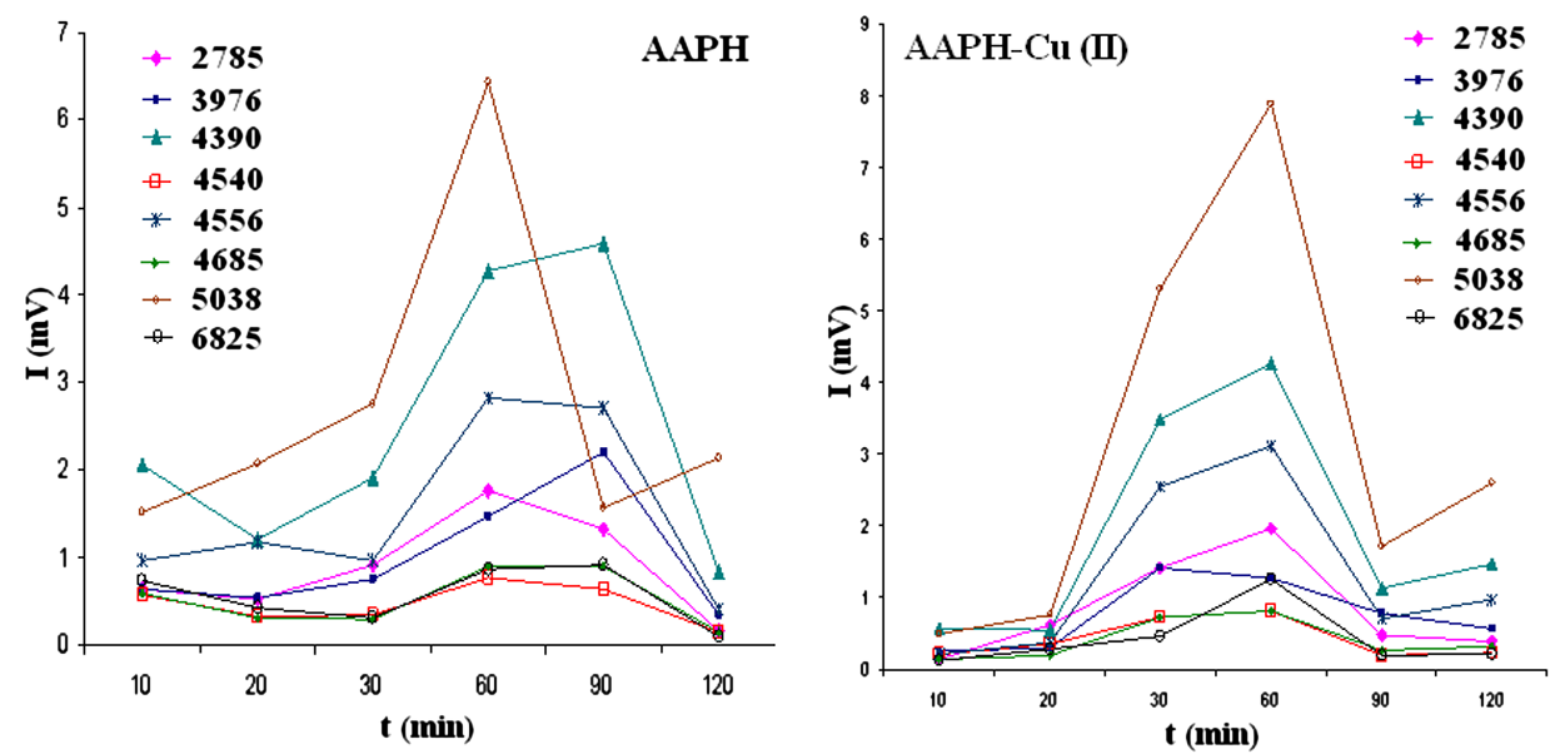

Fig. 3. Time-intensity variation of oxidized product. (A) AAPH oxidation; (B) AAPH-Cu oxidation. (Colors are visible in the online version of the article; http://dx.doi.org/10.3233/SPE-2011-0533.)

suddenly increased for $60 \mathrm{~min}$ and decreased up to $90 \mathrm{~min}$. The 3976 and $4390 \mathrm{Da}$ ion fragments intensity increased for $90 \mathrm{~min}$ and then decreased.

As a consequence of these observations it could be said that the LDL mass fragments reacted differently with the oxidizing agent. Three oxidation steps could be detected: early period, 10-30 min, may be considered the initiation stage of oxidation process, the second period of 30-90 min may be considered the propagation stage and the last one, the termination stage of the oxidation process. 
It was noticed that when the oxidation process is initiated in the presence of the transitional metal ion copper (II), LDL behaves differently (Fig. 3B). Considering the previous defined oxidation steps it could be noticed that the initiation stage of oxidation process is about $20 \mathrm{~min}$. The intensities of LDL oxidation products signals increased for $60 \mathrm{~min}$ and then began to decrease; the exception being the $3976 \mathrm{Da}$ ion fragment, whose maximum peak intensity was obtained at $30 \mathrm{~min}$. The 4540 and $4685 \mathrm{Da}$ ion fragments intensities increased for $30 \mathrm{~min}$ and remained almost constant until $60 \mathrm{~min}$ and then decreased. Therefore, copper ions (II) act as catalysts, increasing the reaction rate of the oxidation process.

It was noticed that, if AAPH was used as initiator of the oxidation process, the resulting fragments that have molecular weight smaller than 4000 Da shown more intense signals than those obtained from oxidized samples in presence of transitional metal ion that shown more intense signal for fragments with molecular mass greater than $4000 \mathrm{Da}$.

Living organisms have developed a complex antioxidant system to counteract the harmful effects of free radicals. Balance between anti-oxidants and pro-oxidant is very important in protecting macromolecules that are subjected to oxidative stress. Balance maintaining is achieved by using compounds with antioxidant properties. Thus it was tested the action of glutathione in order to assess the protective effect against ROS.

After LDL incubation in GSH solution we noticed a modification of some ion fragments intensities (Fig. 4B). However it cannot clearly discriminate between LDL and LDL-incubated in GSH samples because no apparent changes in molecular weight of LDL fragment occur, and due to limitation in the interpretation of MALDI MS spectra on small ranges (1-1000 Da).

LDL subjected to oxidative stress behaves differently in the presence and absence of antioxidant. In the MALDI MS spectra of LDL samples incubated in GSH and further oxidized was noticed (Fig. 4) that: $6810 \mathrm{Da}$ ion fragment signal turned into a shoulder of $6827 \mathrm{Da}$ ion fragment signal, $5273 \mathrm{Da}$ ion fragment does not register significant changes; 4650 and 4522 Da ion fragments greatly decreased

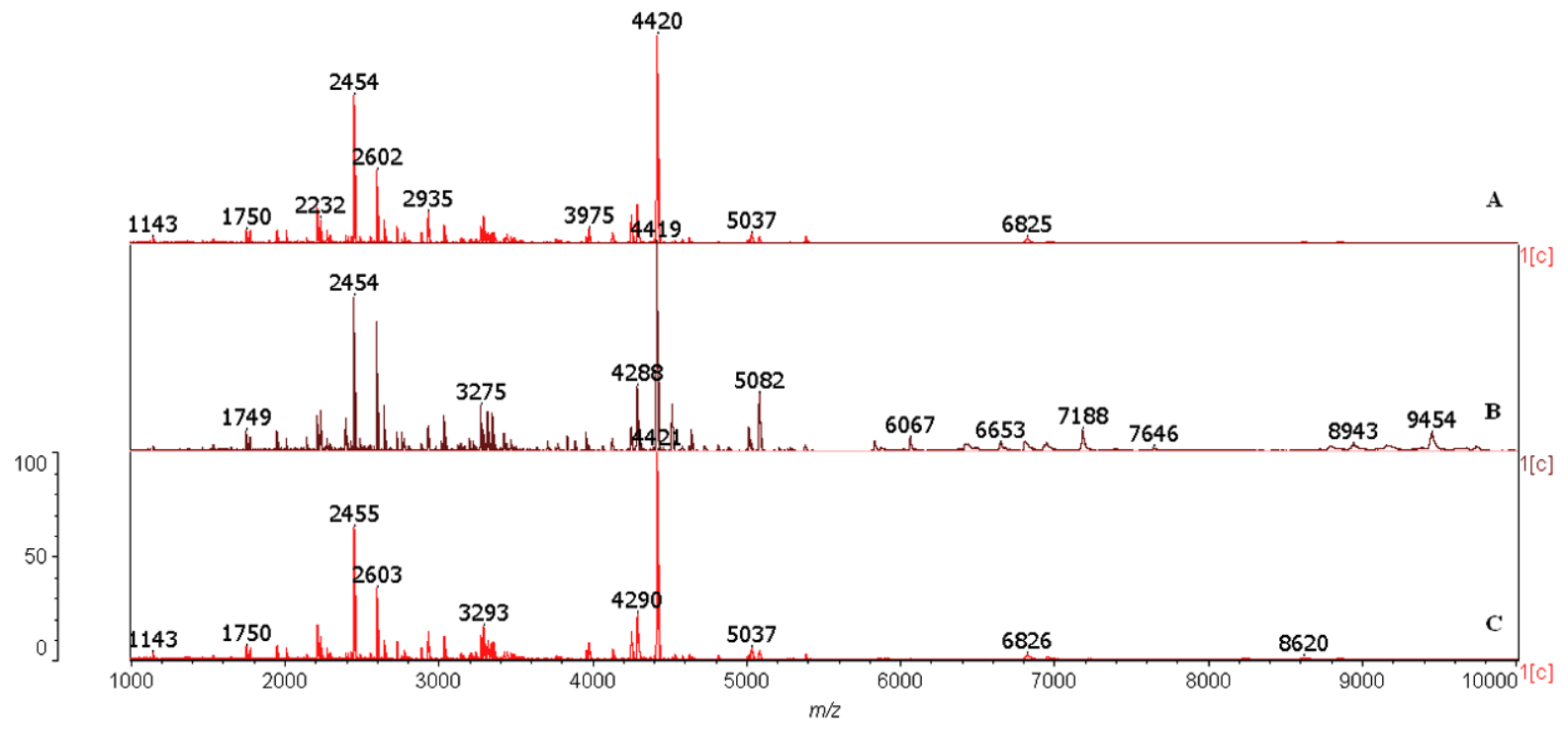

Fig. 4. MALDI MS spectra: (A) LDL incubated in GSH and oxidized in AAPH; (B) LDL incubated in GSH; (C) LDL incubated in GSH and oxidized in AAPH-Cu mixture. (Colors are visible in the online version of the article; http://dx.doi.org/10.3233/ SPE-2011-0533.) 
in intensity, appearing 4665 and $4537 \mathrm{Da}$ ion fragments while $4553 \mathrm{Da}$ ion fragment is poorly visible when AAPH-Cu(II) mixture was used to initiate the oxidation process (4681 Da ion fragment does not appear). The other ions of interest were subjected to a smaller degree of intensities decreasing with respect to signals obtained from oxidized LDL samples in the absence of Aox. On this type of samples ROS effects were diminished. GSH shown a selective preservative effect, depending on the type of oxidative reagent, namely when oxidation is performed solely by AAPH - thermal generated peroxyl, the highest GSH protective against oxidative stress is pronounced for fragments ranging between 4000 $5000 \mathrm{Da}$, while in the case of AAPH-Cu oxidation the better protective is ensured for fragments ranging between 1000-4000 and 5000-10,000 Da.

Another interesting conclusion is that GSH has an antioxidant character against peroxy radicals and it can be noticed from the fact that after oxidative stress the number of fragments whose molecular mass changed with 32 Da has decreased for the LDL samples incubated in GSH solution.

\subsection{FT-IR analysis}

To confirm the obtained data, infrared spectrometry studies were conducted. After performing the oxidation process it was noticed that the FT-IR spectra of LDL/Au samples changed. FT-IR spectra of oxidized LDL/Au (Fig. 5) confirmed the formation of LDL lipoperoxides and provided information about protein conformation change during oxidation.

The increase in AAPH concentrations leads to a corresponding increase in the absorption bands intensity and in their shoulders. Absorption band at $3278 \mathrm{~cm}^{-1}$ increased in intensity and shown shoulders at: $3334,3304,3220$ and $3197 \mathrm{~cm}^{-1}$ assigned to vibrations of $\mathrm{N}-\mathrm{H}$ and $\mathrm{O}-\mathrm{H}$ bonds [1] from protein structure and lipo(hydro)peroxide. The shoulder observed at $3072 \mathrm{~cm}^{-1}$ due to vibrations corresponding to hydroxyl or amino groups involved in intermolecular bonds become an intense band. The absorption band at $3010 \mathrm{~cm}^{-1}$ assigned to vibrations corresponding methyl groups attached to unsaturated carbon atoms turned (slightly) into a shoulder. New absorption bands appeared at 2788, 2734 and $2693 \mathrm{~cm}^{-1}$, being assigned to vibrations due to methyl groups. Vibration band assigned to carbonyl groups of lipid residues from $1736 \mathrm{~cm}^{-1}$ shown a shoulder at $1717 \mathrm{~cm}^{-1}$, which indicated the formation of new carbonyl groups assigned to aldehydes and ketones [30].

Amide I band changed its shape (is intensified and broader) and position. This absorption band is sensitive to protein secondary structure. This means that LDL structure dramatically changed following the radical attack. If the absorption band had an initial peak at $1654 \mathrm{~cm}^{-1}$, in the oxidation process peak becomes shoulder, the absorption band at $1626 \mathrm{~cm}^{-1}$ intensified and maximum occurred at $1679 \mathrm{~cm}^{-1}$. These absorption bands were highlighted after LDL subjection to oxidative stress and were assigned to $\beta$-sheet and $\beta$-turn conformation $[8,11,16]$ respectively. Amide II band also changed, the initial peak (at $1541 \mathrm{~cm}^{-1}$ ) assigned to $\mathrm{N}-\mathrm{H}$ bonds vibration almost disappeared, and the shoulder at $1521 \mathrm{~cm}^{-1}$ significantly increased in intensity.

Other absorption bands that changed due to the oxidation process are: the absorption band from $1462 \mathrm{~cm}^{-1}$ assigned to the scissoring vibration of methylene groups became broader and split into two unresolved peak. The absorption band from $1365 \mathrm{~cm}^{-1}$ assigned to bending vibrations of methyl groups increased; this means that the number of methyl groups increased. The absorption band from $1215 \mathrm{~cm}^{-1}$ assigned to $\mathrm{C}-\mathrm{O}$ bond stretching vibrations of alcohols and peroxides significantly increased in intensity and transformed in a shoulder the absorption band from $1241 \mathrm{~cm}^{-1}$ assigned to phospholipids. The absorption band from $1169 \mathrm{~cm}^{-1}$ assigned to the asymmetric stretching vibrations of CO-O-C groups shifted to higher frequencies and split into two unresolved peaks. A new absorption band appeared at 

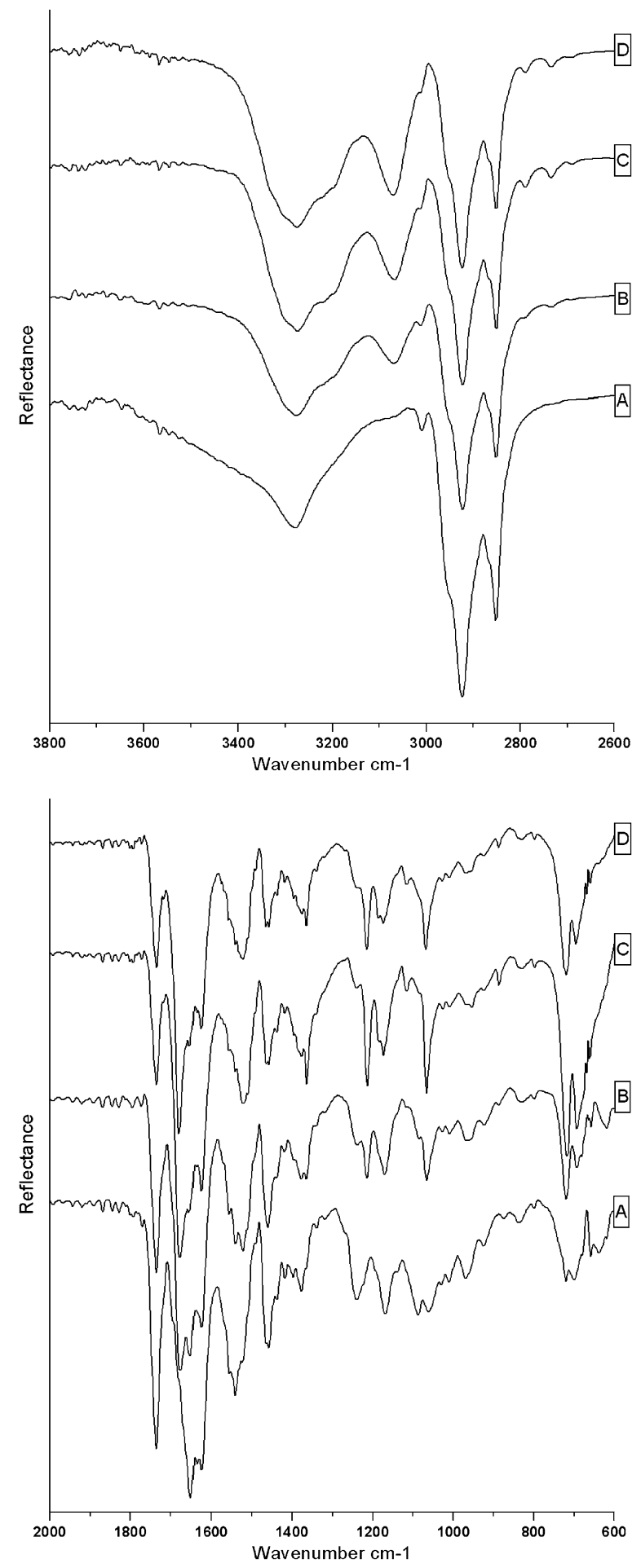

Fig. 5. Details of FT-IR spectra of oxidized LDL on gold supports, (top) wavenumber region 3800-2600 $\mathrm{cm}^{-1}$; (bottom) wavenumber region 2000-600 $\mathrm{cm}^{-1}$; (A) $0 \mathrm{mM} \mathrm{AAPH;} \mathrm{(B)} 7.35 \mathrm{mM}$ AAPH; (C) $36.76 \mathrm{mM}$ AAPH; (D) $73.53 \mathrm{mM}$ AAPH. (Colors are visible in the online version of the article; http://dx.doi.org/10.3233/SPE-2011-0533.) 
$1115 \mathrm{~cm}^{-1}$ and was assigned to $\mathrm{C}-\mathrm{O}$ bond stretching vibrations. Intensity of the absorption band from $1061 \mathrm{~cm}^{-1}$ assigned to the symmetric stretching vibrations of $\mathrm{CO}-\mathrm{O}-\mathrm{C}$ groups increased and sifted to the left at $1068 \mathrm{~cm}^{-1}$, while absorption band from $1087 \mathrm{~cm}^{-1}$ assigned to stretching vibrations of $\mathrm{PO}^{2-}$ groups turned into a shoulder. The absorption band from $969 \mathrm{~cm}^{-1}$ attributed to the bending vibrations of methyl groups split into two peaks. A new absorption band appeared at $887 \mathrm{~cm}^{-1}$, which was assigned to the stretching vibration of the peroxide $\mathrm{O}-\mathrm{O}$ bonds. The intensity of absorption band from $720 \mathrm{~cm}^{-1}$ assigned to bending vibrations of methylene groups increased, and also the intensity of absorption band from $695 \mathrm{~cm}^{-1}$ assigned to vibrations quaternary ammonium salt increased.

As consequence, it should be mentioned that a shift of frequencies toward higher values is given by the presence of electronegative substituents. Higher the electro-negativity is, higher is the noticed frequencies shift.

In a study on structural oxidative changes of LDL/Au in time (data not shown) we noticed that in the first 10-30 min structural changes were similar, then (up to $60 \mathrm{~min}$ ) were more pronounced and after that were attenuated (up to $90 \mathrm{~min}$ ). Shoulder from $1717 \mathrm{~cm}^{-1}$ made an exception (it intensifies).

FT-IR spectra revealed significant differences between the intensity and the position or shape of the LDL absorption bands before and after subjection to free radical attack. In the oxidative process protein secondary structure changed from predominant $\alpha$-helix to predominant $\beta$-turn. If free radicals actions on LDL substrate were longer or more intense, the oxidative effects were stronger.

When copper transitional metal ion $(5 \mu \mathrm{M})$ was present in the system used to initiate LDL oxidation process, oxidative changes were more intense. It was noticed in the FT-IR spectra of LDL/Au oxidized with AAPH-Cu(II) mixture that the absorption band from $3276 \mathrm{~cm}^{-1}$ is broader and its shoulders: $3199,3220,3307$ and $3336 \mathrm{~cm}^{-1}$ were more intense. The intensity of the absorption bands assigned to methylene groups from 2924 and $2852 \mathrm{~cm}^{-1}$ were diminished probably due to damages of lipid structure and shoulders assigned to asymmetric and symmetric stretching vibrations of methyl groups were more intense, and also the absorption band from $1717 \mathrm{~cm}^{-1}$; the absorption band from $1463 \mathrm{~cm}^{-1}$ broadens. In this case, it was also noticed that the LDL layers subjected to oxidative stress for a longer period of time lead to an increase of oxidative modifications. Increasing of copper (II) concentrations in the oxidation system lead to LDL structural degradation (Fig. 6).

The absorption bands from 3500 to $3100 \mathrm{~cm}^{-1}$ become broaden. The absorption bands assigned to stretching vibrations of methylene groups of lipid changed significantly (broaden and decrease in intensity) indicating the alteration of lipid chain and also the absorption band assigned to carbonyl groups of lipid residues decreased. The amide II band changed its shape and position; at low concentrations $(<30 \mu \mathrm{M})$ a peak appeared at $1521 \mathrm{~cm}^{-1}$, and at higher concentrations $(>30 \mu \mathrm{M})$ another one appeared at $1512 \mathrm{~cm}^{-1}$.

FT-IR spectra of LDL chemically modified gold supports incubated in GSH (Fig. 7A) shown the LDL specific absorption bands and some of Aox absorption bands, which lead us to conclusion that LDL quickly interacted with this compound. In a relatively short incubation period (60 min), GSH characteristic FT-IR bands was noticed; after 120-180 min of incubation the absorption bands attributed to GSH were intensified, and after 240 min LDL FT-IR spectra undergo major changes.

After the incubation of LDL/Au bio-mimetic system with GSH, it can be noticed in FT-IR spectra the specific antioxidant absorption band from $2525 \mathrm{~cm}^{-1}$ attributed to thiol groups vibrations, that was shifted with $10 \mathrm{~cm}^{-1}$ towards lower frequencies (due to hydrogen bindings), and the broad absorption band from $1997 \mathrm{~cm}^{-1}$ corresponding to free amino acid residues. Amide I band slightly changed, which means that the protein conformation has not modified in great extent. The absorption bands from 1000$1300 \mathrm{~cm}^{-1}$ slightly decreased in intensity. 


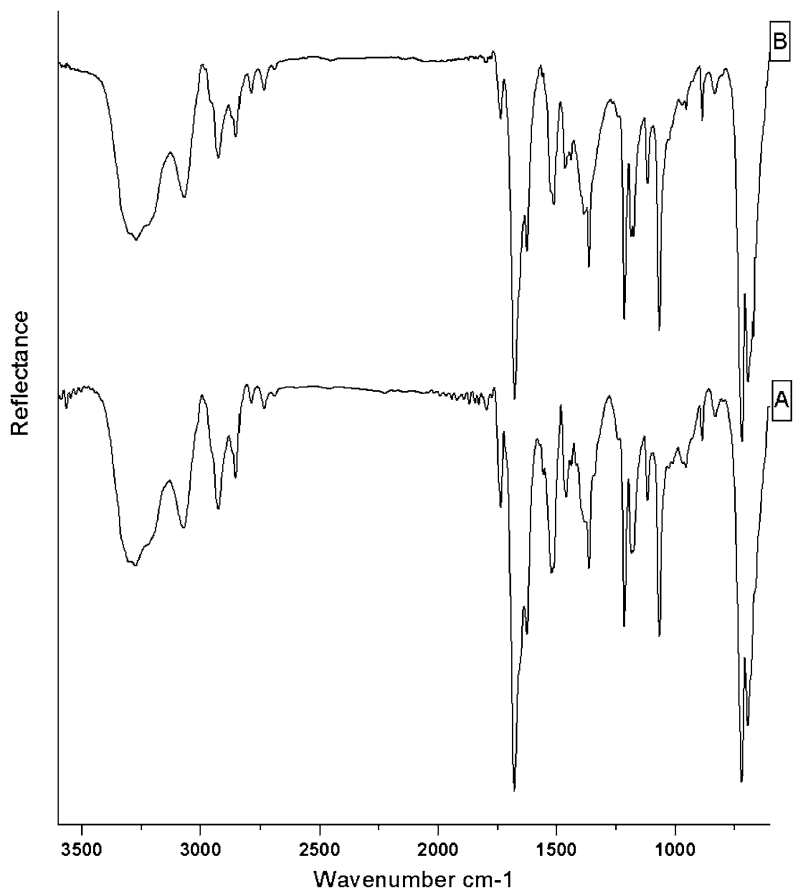

Fig. 6. LDL/Au FT-IR spectra subsequent AAPH-Cu(II) mixture oxidation: (A) $5 \mu \mathrm{M} \mathrm{Cu}$ (II), (B) $30 \mu \mathrm{M} \mathrm{Cu(II).} \mathrm{AAPH} \mathrm{con-}$ centration was kept constant.

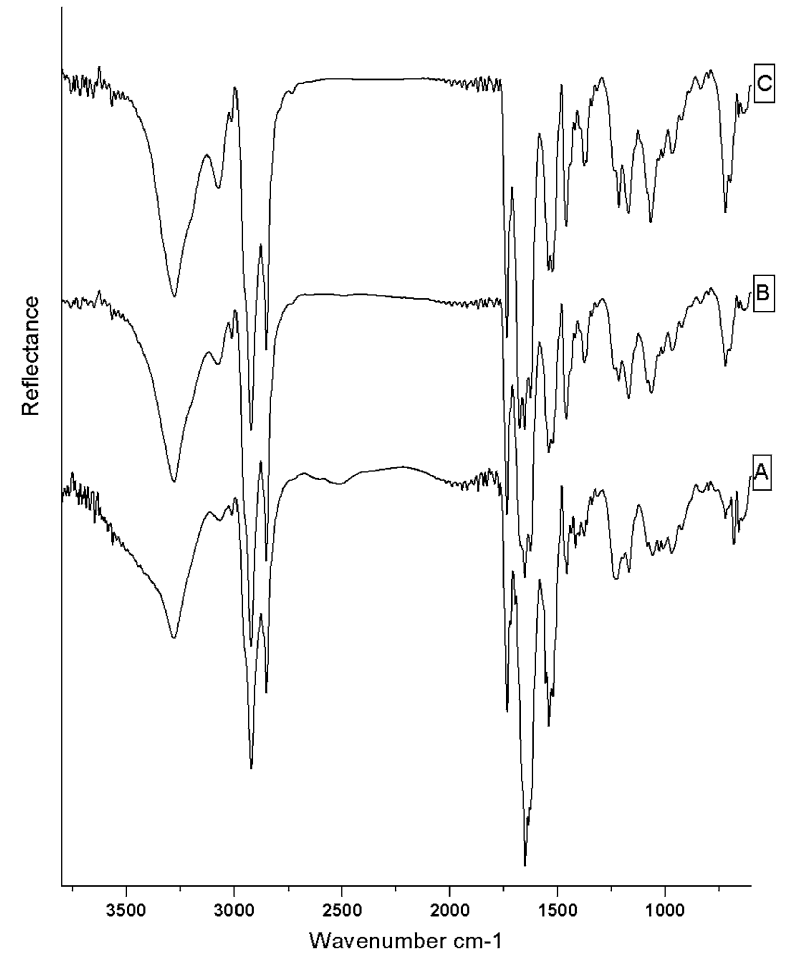

Fig. 7. FT-IR spectra of LDL/Au incubated in GSH: (A) un-oxidized LDL; (B) AAPH oxidized LDL; (C) AAPH-Cu(II) oxidized LDL. 
LDL/Au samples obtained after incubation process in GSH were subjected to oxidation in the presence of AAPH (Fig. 6B), and respectively AAPH-Cu(II) mixture (Fig. 6C). It was noticed that GSH prevent the LDL oxidation. Thus the absorption band from $3279 \mathrm{~cm}^{-1}$ shown a single shoulder at $3192 \mathrm{~cm}^{-1}$; the absorption band from $3010 \mathrm{~cm}^{-1}$ was not turn into a shoulder; the weak band from $2693 \mathrm{~cm}^{-1}$ not appeared and the absorption band from $2788 \mathrm{~cm}^{-1}$ appeared (only) in the presence of copper. Antioxidant specific absorption bands $\left(2525\right.$ and $\left.1997 \mathrm{~cm}^{-1}\right)$ diminished and even disappeared in the presence of copper, which demonstrated that GSH interacted to ROS before the attack of the substrate. The amide I band changed its shape, but the peak remained at $1652 \mathrm{~cm}^{-1}$, which means that $\alpha$-helix protein conformation was still predominant, but its percentage was diminished, while $\beta$-turn conformation percentage increased. Also, the amide II band changed, but the peak remained at $1541 \mathrm{~cm}^{-1}$. The absorption band from $887 \mathrm{~cm}^{-1}$ which occurred when the oxidation of LDL was initiated by AAPH or AAPH-Cu mixture was no longer observed in the FT-IR spectra of oxidized LDL/Au samples that have been incubated previously in an antioxidant solution.

Protective effect of GSH is different depending on the oxidation conditions. When the copper metal ion was present the damaging effects of ROS were more pronounced. This was due to the metal coordination in GSH, blocking the active groups.

\section{Conclusions}

Our experiments performed by MALDI-ToF analysis provided evidence on compositional modification of LDL subsequent peroxidation initiated by thermally generated peroxyl radicals. Moreover, it was proven that $\mathrm{Cu}(\mathrm{II})$ presence in oxidation mixture enhanced the degree of structural damaging. MALDIToF and FT-IR data confirmed the radical mechanism of LDL peroxidation and generally the maximum intensity signal of peroxides starts from $60 \mathrm{~min}$. By using IR spectroscopy we could differentiate between the conformations that LDL adopted and also we could monitor the changes in absorption bands ascribed to the oxidation products (absorption bands assigned to $\mathrm{R}-\mathrm{O}, \mathrm{C}=\mathrm{C}, \mathrm{R}_{2} \mathrm{C}=\mathrm{O}$ vibration). These modifications can be used as markers for free radical actions.

Experimental data provided evidence of the glutathione (thiolic compound) protecting effect on LDL substrate against free radicals. The used antioxidant delayed but not completely prevented the oxidation process.

\section{Acknowledgements}

This work was financial supported by project IDEI 241/2007. PhD Sandra A.V. Eremia is acknowledged for providing language help and writing assistance.

\section{References}

[1] S.B. Akkas, M. Severcan, O. Yilmaz and F. Severcan, Food Chem. 105 (2007), 1281-1288.

[2] M.Z. Ashraf, N.S. Kar and E.A. Podrez, Int. J. Biochem. Cell Biol. 41 (2009), 1241-1244.

[3] W. Cao, W. Chen, S. Sun, P. Guo, J. Song and C. Tian, J. Mol. Struct. - Theochem. 817 (2007), 1-4.

[4] A. Català, Int. J. Biochem. Cell Biol. 38 (2006), 1482-1495.

[5] J. Chaudière and R. Ferrari-Iliou, Food Chem. Toxicol. 9, 10 (1999), 949-962.

[6] A. Dayangac, M. Bahsi, A. Ozkaya and O. Yilmaz, J. Anim. Vet. Adv. 10 (2011), 1232-1238. 
[7] A. Dogan, G. Siyakus and F. Severcan, Food Chem. 100 (2007), 1106-1114.

[8] C.A. Firth, E.M. Crone, E.A. Flavall, J.A. Roake and S.P. Gieseg, Biochem. Biophys. Acta 1783 (2008), 1095-1101.

[9] B. Halliwel and J.M.C. Gutteridge, Free Radicals in Biology and Medicine, 4th edn, Oxford Univ. Press, New York, 2007, pp. 502-505.

[10] A.A. Hamid, O.O. Aiyelaagbe, L.A. Usman, O.M. Ameen and A. Lawal, AJPAC 4 (2010), 142-151.

[11] M. Jackson and H.H. Mantsch, Can. J. Chem. 69 (1991), 1639-1642.

[12] A. Jeneri, T.G. England, O.I. Aruoma and B. Halliwell, Biochem. J. 331 (1998), 365-369.

[13] M. Kinter, J. Chromatogr. B 671 (1995), 223-236.

[14] R.H. Knopp, P. Paramsothy, B. Atkinson and A. Dowdy, Am. J. Cardiol. 101 (2008), S48-S57.

[15] S. Kohri, H. Fujii, S. Oowada, N. Endoh, Y. Sueishi, M. Kusakabe, M. Shimmei and Y. Kotake, Anal. Biochem. 386 (2009), 167-171.

[16] J. Kong and S. Yu, Acta Biochem. Biophys. Sin. 39 (2007), 549-559.

[17] Kontush, T. Spranger, A. Reich, S. Djahansouzi, B. Karten, J.H. Braesen, B. Finckh, A. Kohlschütter and U. Beisiege, BioFactors 6 (1997), 99-109.

[18] M. Laguerre, J. Lecomte and P. Villeneuve, Prog. Lipid Res. 46 (2007), 244-282.

[19] K.-S. Lee, K. Lee, V. Lau, K. Shin and B.-K. Ju, WASET 74 (2011), 385-388.

[20] A. Liu and Y.A. Hannun, J. Biol. Chem. 272 (1997), 16281-16287.

[21] J.-P. Mattila, K. Sabatini and P.K.J. Kinnunen, Biophys. J. 93 (2007), 3105-3112.

[22] B. Muik, B. Lendl, A. Molina-Diaz, M. Valcarcel and M.J. Ayora-Cañada, Anal. Chim. Acta 593 (2007), 54-67.

[23] E. Niki, Method. Enzymol. 186 (1990), 100-108.

[24] B. Ou, D. Huang, M. Hampsch-Woodill, J.A. Flanagan and E.K. Deemer, J. Agric. Food Chem. 50 (2002), 3122-3128.

[25] G. Pankhurst, X.L. Wang, D.E. Wilcken, G. Baernthaler, U. Panzenböck, M. Raftery and R.Stocker, J. Lipid Res. 44 (2003) 349-355.

[26] P. Pedrielli, L.M. Holkeri and L.H. Skibsted, Eur. Food Res. Technol. 213 (2001), 405-408.

[27] F.D. Porter, D.E. Scherrer, M.H. Lanier, S.J. Langmade, V. Molugu, S.E. Gale, D. Olzeski, R. Sidhu, D.J. Dietzen, R. Fu, C.A. Wassif, N.M. Yanjanin, S.P. Marso, J. House, C. Vite, J.E. Schaffer and D.S. Ory, Sci. Transl. Med. 2 (2010), 56-81.

[28] N. Qu, L.-H. Guo and B.-Z. Zhu, Biosens. Bioelectron. 26 (2011) 2292-2296.

[29] M. Rizzo and K. Berneis, Q. J. Med. 99 (2006), 1-14.

[30] C. Strandberg, L. Burman and A.-C. Albertsson, Eur. Polym. J. 42 (2006), 1855-1865.

[31] N.A. Strobel, R.G. Fassett, S.A. Marsh and J.S. Coombes, Int. J. Cardiol. 147 (2011), 191-201.

[32] M. Sumanth and A.C. Rana, Indian J. Pharmacol. 38 (2006), 54-55.

[33] A.Tache, S. Cotrone, S.-C. Litescu, N. Cioffi, L. Torsi, L. Sabbatini and G.-L. Radu, Anal. Lett. 44 (2011), 747-760.

[34] V.V. Tertov, V.V. Kaplun, S.N. Dvoryantsev and A.N. Orekhov, Biochem. Biophys. Res. Comm. 214 (1995), 608-613.

[35] Y. Tian, R. Liu, W. Zong, F. Sun, M. Wang and P. Zhang, Spectrochim. Acta A 75 (2010), 908-911.

[36] M. Valko, C.J. Rhodes, J. Moncola, M. Izakovic and M. Mazur, Chem. Biol. Interact. 160 (2006), 1-40. 


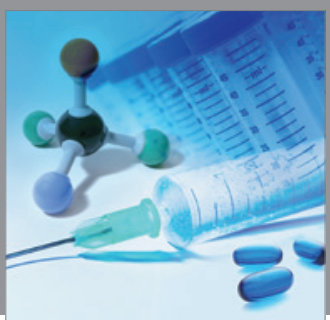

International Journal of

Medicinal Chemistry

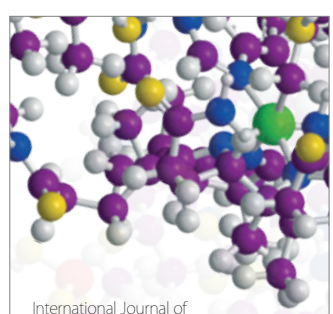

Carbohydrate Chemistry

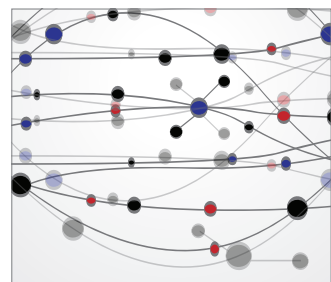

The Scientific World Journal
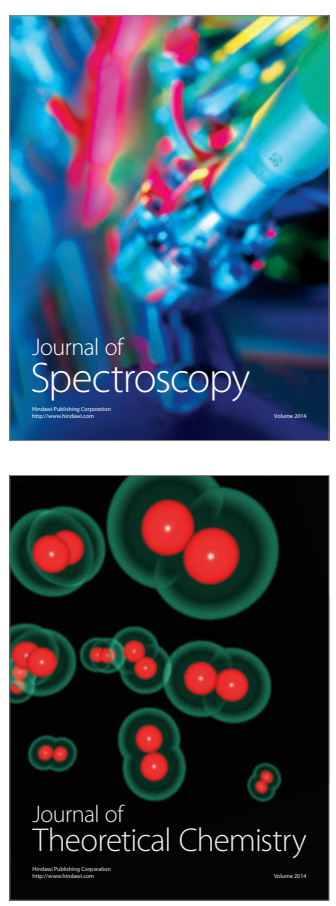
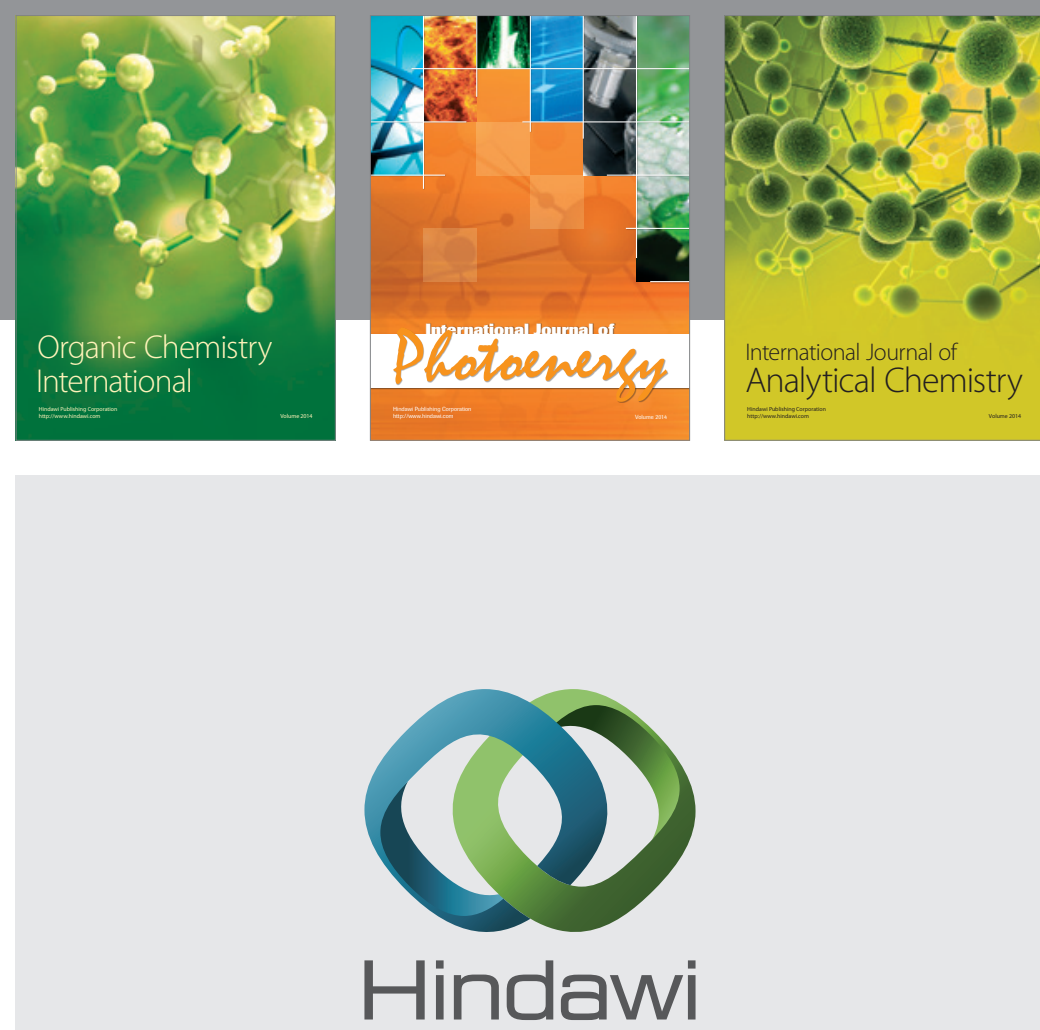

Submit your manuscripts at

http://www.hindawi.com
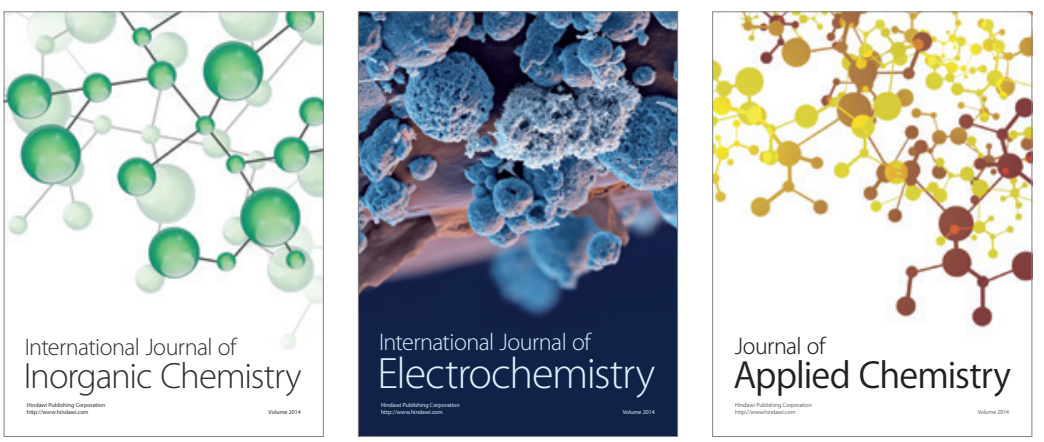

Journal of

Applied Chemistry
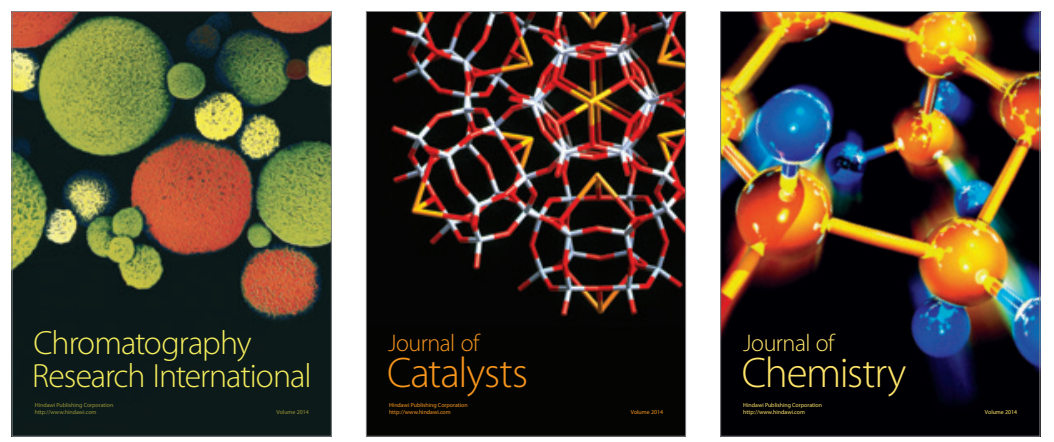
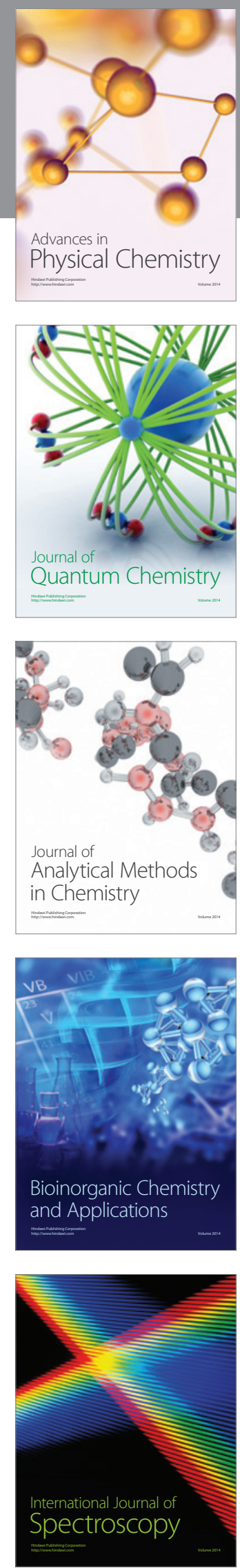